\section{The Farmer and the Hacker}

People have warned against "monoculturalism" in the software community for years. Parallels have been drawn between Internet viruses and worms such as ILOVEYOU and Microsoft SQL Slammer and, for example, the Mexican boll weevil that devastated cotton plantations in the American South.

The U.S. cotton industry is still paying the price for naively favoring a single, very profitable, type of cotton in the days of yore. Software designers, what can be done?

Sun Microsystems has already been warning against the commercial domination of a single software or hardware product. There have been attempts made to introduce diversity into software programs manually by assigning the same project to different teams. No surprise, that was expensive and time-consuming.

Now the focus is on finding a more economic and automated approach that rearranges a program's layout below the interface. This is what the NSF (National Science Foundation) is banking its money on-to the tune of \$750,000 grants awarded to Carnegie Mellon University and the University of New Mexico. And, of course, they're also studying the feasibility of creating patches for all of those software versions.

WANT MORE?

http://news.com.com/2009-7349_3-5140971.html?

tag=nefd_lede

http://washingtontimes.com/upi-breaking/

20031125-040116-1419r.htm

\section{Milk and Algorithms Make for Strong Bones}

Researchers at Los Alamos National Laboratory's Theoretical and Applied Physics divisions want to learn more about bone remodeling and are using an Absoft compiler to spin up the old Monte Carlo analysis algorithms developed by the same lab during the 1940s.

It turns out natural bone growth not only takes place during childhood (a natural growth period), but also comes about as a result of exercise, recovery from injuries, and hormonal changes. And everyone loses bone mass as they age: Women experience rapid bone loss as a result of menopause, and today's man (sedentary, longer-living) is

\section{Taking a second look AT}

THE NEWS SO YOU

DON'T HAVE TO

more likely to be diagnosed with the ailment (bone loss of course, not menopause) than in the past.

Because Monte Carlo analysis techniques were used in such complex projects as developing the atomic bomb, this bone stuff should be a slam dunk, right? Don't throw out your grandparents' walkers just yet. It has also been used by financial types to predict the stock market-need we say more?

WANT MORE?

http://www.lanl.gov/quarterly/q_w03

bones.shtml\#structure

\section{Keep Your Distance!}

Soon we'll be receiving plastic cards to replace our plastic cards. Imagine the following promotion: Your credit card of the future will come with an embedded RFID (radio frequency identification) device that will swiftly take care of your transaction simply via the ether. No signature or PIN required. No need to take your card from your wallet and "swipe" it through a card reader. In fact, no need even to take out your wallet! These "contactless" cards will save you valuable time so that you will be at your leisure to spend even more money.

Sounds like a win/win/win situation for shoppers, vendors, and credit card companies, right? But if a merchant can read your credit card while it's still in your wallet, who's to stop ne'er-do-wells from following mall rats and soccer moms around ringing up plasma TVs? Grocery store shoppers, who already are challenged to make sure that nobody in the checkout line steals their credit card number or PIN, will literally be eyeballing everything within range. Identity theft in the elevator, who knew?

WANT MORE?

http://news.com.com/2100-7353_3-5137952.html?

tag=prntfr

http://www.eurosmart.com/meiji/download/March2003/ TK_0303_SecWs_Handschuh.pdf $Q$

\section{LOVE IT, HATE IT? LET US KNOW}

feedback@acmqueue.com or www.acmqueue.com/forums 